\title{
PENGARUH LINGKUNGAN KERJA, MOTIVASI KERJA TERHADAP KINERJA KARYAWAN PADA CABANG PT. BNI, Tbk. KOTA MEDAN
}

\author{
YOVIE ERNANDA, SARI SUSANTI SIMAMORA, ARAVENTA SIOLINA BR SEMBIRING \\ MELIALA, HERRY IVAN NATHANAEL SITOMPUL, SRI FATMAWATI \\ Universitas Prima Indonesia \\ Email: yoviernanda@yahoo.com, sari.susanti57@yahoo.co.id, \\ araventasiolina384@gmail.com, ivanharry3@gmail.com, \\ srifatmawati2010@gmail.com
}

(Article History)

Received September 04, 2020; Revised November 10, 2020; Accepted November19, 2020

\begin{abstract}
:
This study aims to see how the work environment influences, work motivation on the performance of the bank employees. The influential subjects in this study were the bank employees with 70 respondents. By collecting interview data, distributing questionnaires, as well as literature study which is also equipped with related tests, namely: validity tests, reliability tests, hypothesis test, and coefficient of determination. And calculated using SPSS 23 aims to get accurate results in order to draw conclusions whether this influence is a positive or negative influence on employee performance at the branch of PT BNI, Tbk. Medan. So it can be concluded that the work environment with work motivation does or does not significantly affect the performance of employees at branch of PT BNI, Tbk. Medan.
\end{abstract}

Keywords: Effect of Work Environment, Motivation, Employee Performance

\section{PENDAHULUAN}

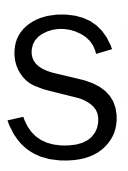
umber daya manusia merupakan salah satu faktor penting dalam pembangunan yang utama yang tidak hanya terdiri dari pelatihan dan pengembangan, tetapi juga perencanaan karier individual dan aktivitas organisasi (Samsudin, 2010). Pelatihan sumber daya manusia adalah proses peningkatan keterampilan teknik dan moral karyawan melalui pendidikan dan pelatihan organisasi (Sinambela, 2016). Kedua hal yang merupakan tersebut di atas dipandang perlu pada dunia perbankan, seperti pada cabang PT. Bank Negara Indonesia (BNI), Tbk. Medan, karena perusahaan ini adalah sebuah organisasi pemerintahan yang hadir sebagai salah satu perusahaan terkemuka dalam hal kepentingannya untuk memberikan pelayanan yang terbaik kepada masyarakat (public service).

Cabang PT. BNI, Tbk. Medan yang didirikan pada tahun 1963 hingga saat sekarang ini adalah merupakan sebuah organisasi pemerintah yang mempunyai tugas di bidang perbankan atau yang disebut bank simpan-pinjam uang yang 
diberlakukan terhadap seluruh masyarakat yang disalurkan oleh Bank Indonesia (BI) dengan aturan yang dikeluarkan dan diberlakukan oleh pemerintah yang tertera dalam peraturan UU Nomor 2 Tahun 1946. Dalam rangka menjalankan tugas tersebut organisasi ini membutuhkan sumber daya manusia untuk bekerja secara efektif dan efisien. Ada beberapa faktor yang menentukan apakah kinerja karyawan bermanfaat bagi perusahaan, antara lain lingkungan kerja dan motivasi kerja yang akan didukung dengan beberapa indikator yang berasal dari kedua variabel untuk mengevaluasi hasil kinerja karyawan. Yang termasuk permasalahan salah satu evaluasi dari segi motivasi yaitu adalah Sasaran Kinerja Pegawai (SKP) dikarenakan lingkungan kinerja yang kurang mendukung dengan fasilitas yang kurang pada salah satu cabang PT. BNI, Tbk. Medan.

Fenomena berdasarkan SKP di PT. BNI, Tbk. menurut dari beberapa karyawan yang termasuk dalam sampel 70 karyawan dengan metode wawancara dan pernyataan dari kuesioner, ditemukan bahwa lingkungan kerja kurang nyaman karena kurangnya fasilitas yang diberikan perusahaan seperti lahan parkir, karena kantor tidak cukup luas yang terletak di pinggir jalan dan satu lokasi dengan kampus negeri Medan yaitu USU, toilet yang kurang bersih karena cleaning service tidak membersihkan setiap hari, tetapi hanya 2 hari sekali, sedangkan karyawan yang sebanyak itu mungkin saja memakai kamar mandi setiap jamnya dengan memakai alas kaki atau sepatu ke dalam toilet yang datang dari luar tempat kerja maupun yang sudah di dalam tempat kerja, dan penerangan yang kurang memadai karena pada siang hari mereka tidak menghidupkan semua lampu dikarenakan bantuan cahaya dari luar lokasi yang dipancarkan dari jendela.

Satu hal ini dapat mempengaruhi baik atau tidaknya kinerja karyawan dalam hal menciptakan pengembangan sumber daya manusia yang berkualitas. Menurut beberapa karyawan, motivasi yang diberikan cukup bagus dan berhasil tetapi hanya bagi karyawan yang mendapatkan upah lebih besar dan insentif lebih banyak, juga pegawai lama. Hasil wawancara awal dikatakan bahwa cukup untuk mendukung kualitas mereka bekerja dan mencapai target yang diinginkan apalagi dengan bonusbonus tahunan atau tunjangan hari raya. Sementara pegawai baru mengatakan hal ini menjadi suatu kesenjangan atau ketidakseimbangan di dalam menciptakan kinerja yang diharapkan karena upah yang mereka dapatkan tidak sebanding atau jauh berbeda dengan pegawai lama. Untuk mendapatkan kenaikan jabatan dan menjadi pegawai tetap belum tentu bisa secepat yang dibayangkan, yang selayaknya tidak boleh ada perbedaan. Sesuai dengan standar inilah yang menimbulkan hasil kinerja pegawai rata-rata belum memuaskan, target atau pendapatan perusahaan belum stabil, dan selalu naik-turun di setiap bulannya.

Menurut Armstrong dan Baron dikutip dalam Wibowo (2016) dikatakan bahwa "kinerja adalah pendekatan strategis dan terpadu untuk menyampaikan sukses berkelanjutan pada organisasi dengan memperbaikikarakteristik kerja karyawan 
yang bekerja didalamnya dan dengan mengembangkan kapabilitas tim dan kontributor individu".

Berdasarkan definisi di atas kinerja karyawan dalam cabang PT. BNI, Tbk. Medan yang dihubungkan dengan permasalahan yang ada haruslah seorang manajer atau atasan yang memberikan: (1) Masukan yang berupa kapabilitas SDM baik berupa individu maupun tim; (2) Proses yang dilakukan untuk kebijakan yang ada dan orang mempunyai kesempatan meneliti apa dasar pembuatan keputusan; (3) Umpan balik untuk merencanakan tujuan yang akan datang dan eksekusi kinerja yang telah dikerjakan; (4) Manfaat hasil kerja suatu organisasi merupakan manfaat yang bisa diperoleh dari hasil luar kinerja karyawan, hingga kinerja karyawan bisa berjalan dengan baik dan bisa memenuhi target kinerjanya dengan maksimal.

Lingkungan kerja dapat di artikan sebagai tempat seseorang bekerja. Seperti yang dikatakan oleh Jordan E. Ayan dalam Kaswan (2017) yang dikutip sebagai berikut “Lingkungan meliputi 'jagat kecil' yaitu ruangan, kantor atau rumah tempat kita melewati siang dan malam dan 'jagat besar' yaitu kota, Negara, dan wilayah tempat kita tinggal." Berdasarkan pendapat ini dapat disimpulkan bahwa lingkungan kerja adalah sesuatu yang ada di sekitar lingkungan kerja yang dapat mendukung aktivitas pekerja itu sendiri.

Indikator yang berkaitan dengan lingkungan kerja pada Kantor Cabang PT. BNI, Tbk. Medan meliputi: (1) Ruangan yang nyaman; (2) Pencahayaan yang cukup; (3) Tata ruang yang baik; (4) Ventilasi udara yang baik; dan (5) Lingkungan kerja yang bersih. Dengan demikian karyawan merasa nyaman dan melakukan pekerjaan nya dengan baik.

Menurut TheLiang Gie yang dikutip dalam Hasibuan, (2016), “Motivasi adalah yang dilakukan oleh pekerja manajer yang memberikan inspirasi, dorongan dan semangat kepada orang atau bawahan, dalam keadaan ini diharuskan karyawannya melakukan tindakan tertentu." Jadi, motivasi kerja adalah yang dapat memunculkan dorongan atau semangat kerja. Beberapa diantaranya yang mempengaruhi motivasi kerja adalah atasan, kolega, lingkungan, peraturan, ketidaksesuaian mata uang dan non-mata uang, jenis pekerjaan dan tantangan.

Berdasarkan penjelasan tentang pengertian motivasi kerja, maka dapat disimpulkan bahwa indikator yang berkaitan dengan motivasi kerja yang harus diberikan kantor cabang PT. BNI, Tbk. Medan meliputi: (1) Seorang atasan harus memberikan pengaruh yang baik kepada karyawan bawahannya; (2) Atasan harus memberikan inspirasi dan semangat kepada karyawannya; (3) Atasan harus memberikan fasilitas dan kebijakan yang baik; (4) Selalu ada reward yang diberikan oleh perusahaan bagi karyawan yang berprestasi; dan (5) Selalu memberikan tantangan kepada karyawannya. Dengan demikian karyawan mampu bersaing dengan baik dan meningkatkan produktivitas dari motivasi yang diberikan atasan kepada karyawannya, sehingga karyawan mencapai target pekerjaannya. 
Menurut Lawlen dan Leadpord dalam Kaswan (2017), “Lingkungan kerja adalah segala sesuatu di sekitar pekerja, yang akan mempengaruhi tugas yang diberikan kepadanya, seperti kebersihan, mendengarkan musik, dan lain-lain, sehingga dapat berpengaruh positif terhadap kinerja karyawan." Lingkungan kerja menjadi salah satu hal yang mempengaruhi produktivitas dan semangat kerja karyawan. Tanpa lingkungan kerja yang baik, karyawan akan mudah bosan dan tidak betah untuk bekerja di tempat tersebut.

Menurut Kinicki dan Fugate dalam Marsel (2017), “Memotivasi menjelaskan proses psikologis yang menyebabkan gairah, bimbingan dan kegigihan terhadap pilihan tindakan sendiri yang mengarah pada tujuan atau sasaran." Pemberian motivasi yang tepat akan menimbulkan semangat, kemauan, dan keikhlasan untuk bekerja dalam diri seorang karyawan. Semakin meningkatnya semangat dan kemauan untuk bekerja, maka dapat membuat pekerjaan lebih maksimal, sehingga dapat meningkatkan produktivitas kerja.

Merujuk pada uraian-uraian literatur tentang lingkungan kerja, motivasi dan kinerja bahwa terdapat keterkaitan antara ketiga hal ini. Didukung pula oleh hasil penelitian dari Hia (2018) yang menunjukkan bahwa lingkungan kerja fisik dan disiplin kerja berpengaruh terhadap kepuasan kerja. Oleh karena itu, tujuan dari penelitian ini adalah pertama, untuk memberikan data empiris tentang peningkatan kinerja melalui perbaikan lingkungan kerja dan pemberian motivasi pada PT. BNI, Tbk Medan; dan kedua untuk mengetahui pengaruh lingkungan kerja dan motivasi terhadap kinerja karyawan pada PT. BNI, Tbk Medan.

\section{METODE PENELITIAN}

Jenis penelitian ini adalah penelitian kuantitatif. Penelitian ini dilaksanakan di kantor cabang PT. BNI, Tbk. Kota Medan yang beralamat di Jalan Dr. Mansyur, Padang Bulan, Medan Baru, Kota Medan-Sumatra Utara. Metode pengumpulan data yang digunakan dalam penelitian ini adalah wawancara, penyebaran kuesioner, dan studi kepustakaan. Teknik penentuan sampel menggunakan metode Multiple Stage Sample atau sampel diambil dari kelompok populasi. Selanjutnya, Dalam penentuan sampel terhadap karyawan pada kantor cabang PT. BNI, Tbk. Medan ini tidak semua anggota tim populasi yang diambil jadi sampel, tetapi hanya sebagian dari sub populasi saja, dan untuk itu dari total karyawan yang berjumlah 80 orang sebagai populasi, maka diambil 70 orang yang ditentukan menjadi sampel untuk memenuhi kriteria dalam mencapai hasil yang maksimal pada penelitian dan analisis hasil kinerja pegawai. Setelah mengumpulkan data, selanjutnya digunakan teknik pengelolaan data untuk menganalisis data tersebut dengan metode Multiple Stage Sample. Analisis data yang digunakan adalah metode analisis Statistik dengan menggunakan software SPSS 23. Model analisis data variabel respons sebagai berikut:

$$
y_{\mathrm{ij}}=\mu+\tau_{\mathrm{i}}+\varepsilon_{\mathrm{ij}}
$$


YOVIE ERNANDA, SARI SUSANTI SIMAMORA, ARAVENTA SIOLINA BR SEMBIRING MELIALA, HERRY IVAN NATHANAEL SITOMPUL, SRI FATMAWATI

Keterangan: $\mu=$ Parameter semua perlakuan bisa disebut dengan rata-rata keseluruhan; $\tau_{1}=$ Parameter untuk perlakuan ke-I bisa disebut dengan efek atau pengaruh perlakuan ke-l; $\varepsilon_{\mathrm{ij}}=$ Komponen variabilitas dalam eksperimen dengan asumsi berdistribusi normal, identik, dan mempunyai rata-rata 0 serta varians $\sigma^{2}$

Metode analisis selanjutnya menggunakan uji asumsi klasik, uji hipotesis dan uji korelasi.

\section{HASIL PENELITIAN DAN PEMBAHASAN}

Hasil penelitian dan pembahasan dipaparkan dengan panjang 60-70\% dari panjang badan artikel. Hasil analisis atau penelitian adalah bagian inti dari artikel ilmiah. Hasil analisis atau penelitian umumnya berisikan hasil analisis data, hasil pengujian hipotesis. Untuk memperjelas memaparkan hasil analisis atau penelitian dilengkapi dengan bagan gambar, tabel dan atau grafik.

Dalam analisis deskriptif akan didapatkan jawaban terkecil, terbesar, rata-rata, dan standar deviasi yang dihitung dengan SPSS 23 seperti yang terlihat dari Tabel 1.

Tabel 1. Hasil Perhitungan Statistik

\begin{tabular}{l|c|c|c|c|c}
\hline Variable & Coefficient & Std. Error & t-Statistic & Sig. & $\begin{array}{c}\text { Minimu } \\
\mathrm{m}\end{array}$ \\
\hline $\mathrm{C}$ & 26.109 & 7.609 & 6.431 & 0.000 & 37 \\
X1 & 0.065 & 0.185 & 0.643 & 0.522 & 34 \\
X2 & 0.338 & 0.203 & 3.311 & 0.002 & 36 \\
\hline R-Squered & & & & 0.222 \\
Adjusted R- Squered & & & & 0.199 \\
S.E. of the Estimate & & & & 1.991 \\
Mean Dependent Var & & & & 1.961 .643 \\
S.D. Dependent Var & & & & 0.200 \\
Asymp. Sig. (2-tailed) & & & & 0.714 \\
Tolerance & & & & 2.894 \\
VIF & & & & \\
F-Statistic & & & &
\end{tabular}

Sumber: Data diolah, 2020

Berdasarkan jawaban dari 70 responden, maka hasil pengukuran variabel lingkungan kerja (X1) diperoleh skor terendah sebesar 37, tertinggi 49, rata-rata 42,19 dan standar deviasi 2,789. Variabel motivasi (X2) diperoleh hasil terendah sebesar 34, tertinggi 45, rata-rata 40,27 dan standar deviasi 2,782. Variabel kinerja karyawan (Y) diperoleh hasil terendah sebesar 36, tertinggi 50, rata-rata 42,47 dan standard deviasi sebesar 2,225. Diperoleh Mean Dependent Variable yaitu 41,643. 


\section{Uji Asumsi Klasik \\ Uji Normalitas}

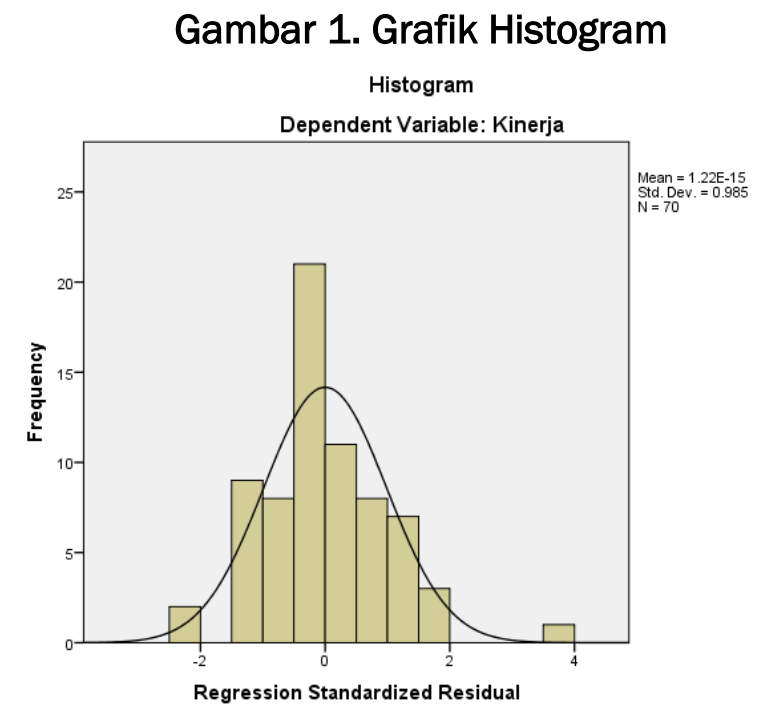

Sumber: Data diolah, 2020

Dalam Gambar 1 distribusi kurva tampak seperti lonceng seimbang kanan-kiri tidak melenceng lebih banyak ke kanan atau ke kiri. Berarti dibuktikan bahwa data terdistribusikan secara normal. Hal ini sesuai dengan yang dikatakan oleh Lieadi (2018).

\section{Kurva Normal p-plot}

\section{Gambar 2. Kurva Normal p-plot}

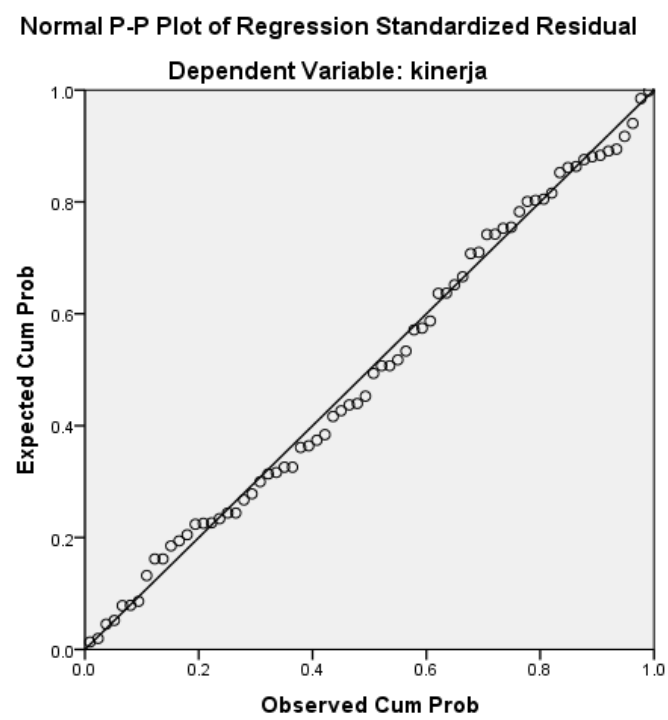

Sumber: Data diolah, 2020

Pada Gambar 2 disimpulkan bahwa penyebaraan titik terdapat di garis diagonal, dengan demikian bahwa data residual sudah berdistribusi normal dan tidak menjauhi garis diagonal tersebut. Hal ini sesuai dengan yang dikatakan oleh Siagian (2017). 
YOVIE ERNANDA, SARI SUSANTI SIMAMORA, ARAVENTA SIOLINA BR SEMBIRING MELIALA, HERRY IVAN NATHANAEL SITOMPUL, SRI FATMAWATI

\section{Uji Kolmogorov-Smirnov}

Uji Komolgorov-Smirnov bertujuan menyusun hipotesis yang dinyatakan $\mathrm{H}_{0}$ : Residual didistribusikan secara normal $\mathrm{H}_{1}$ : Residual tidak didistribusikan secara normal. Dengan memilih tingkat signifikansi $\alpha$ yang keputusan ujinya: jika nilai sama dengan 0,05 < Sig. maka $\mathrm{H}_{0}$ tidak ditolak. Dengan kata lain, data sampel berdistribusi normal (Pramesti, 2016).

Berdasarkan Tabel 1 data dalam model regresi berdistribusi normal karena untuk mendapatkan nilai Asymp Sif (2-tailed) sebesar.200 lebih besar dari 0.05 dengan S.D Dependen variabel sebesar 1.96191821, maka data dinyatakan terdistribusi normal.

\section{Uji Multikolinearitas}

Uji Multikolinearitas dimana kondisinya 2 atau lebih banyak variabel independen. Munculnya multikolinearitas dapat dilihat dari nilai Variance Inflation Factor (VIF), yang merupakan standar deviasi kuadrat dan digunakan untuk mengukur kedekatan hubungan antara variabel independen. Nilai VIF melebihi 10 menunjukkan adanya gejala multikolinearitas (Pramesti, 2016)

Berdasakan Tabel 1 hasil pengujian multiokolinieritas dapat dilihat tolerance setiap variabel independen lingkungan kerja $X_{1}=0,714$, motivasi $X_{2}=0,714$, dimana nilai di atas 0,10 , sedangkan nilai VIF lingkungan kerja $X_{1}=1,402$, motivasi $X_{2}=$ 1,402 yang mana nilainya tidak di atas 10 , maka variabel dapat dinyatakan normal dan tidak terjadi gejala multikolinearitas.

\section{Uji Heteroskedatisitas}

\section{Uji Heteroskedatisitas Secara Grafik}

\section{Gambar 3. Uji Heteroskedastisitas Scatterplot}

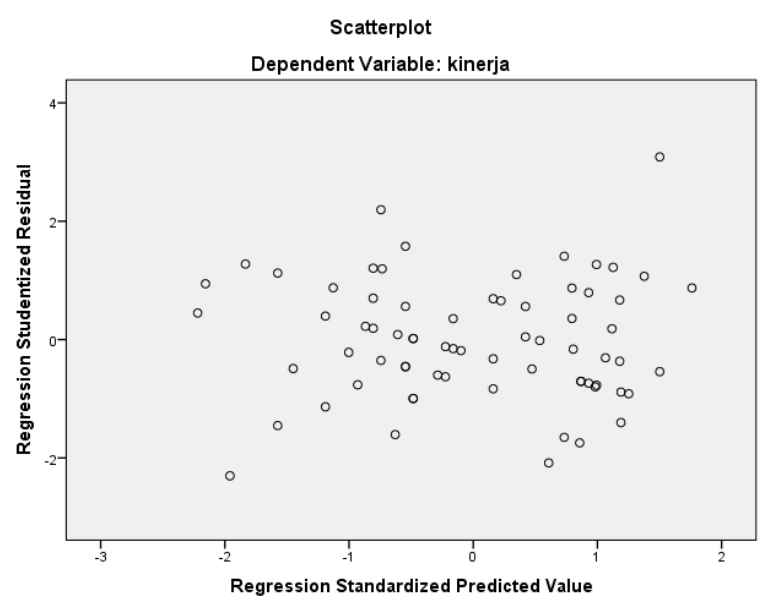

Sumber: Data diolah, 2020

Pada Gambar 3 disimpulkan bahwa data tersebut menyebar tidak teratur dan tidak membentuk pola tertentu dan menjauhi titik 0 . Oleh karena itu dapat diketahui tidak terjadi heteroskedastisitas. 


\section{Uji Heteroskedastisitas Statistik}

Uji Glejser untuk menyusun hipotesis dengan $\mathrm{H}_{0}$ : asumsi homoskedastisitas dipenuhi, $\mathrm{H}_{1}$ : Asumsi homoskedastisitas tidak dipenuhi dan memilih tingkat signifikansi $\alpha$. Yang keputusan ujinya, jika nilainya sama dengan $0.05<$ Sig. maka $\mathrm{H}_{0}$ tidak ditolak. Dengan kata lain, tidak terjadi masalah heteroskedastisitas.

Tabel telah menunjukan nilai yang signifikan dengan variabel bebas lingkungan kerja sebesar $1.492>0,05$ dan variabel bebas motivasi kerja sebesar1.492 > 0,05. Oleh karena hasil dari uji Glejser dapat dikatakan bahwa tidak ada masalah heteroskedastisitas.

\section{Uji Prasyarat Analisis}

Uji prasyarat analisis dilakukan sebelum hipotesis diuji dimaksudkan untuk melihat apakah variabel lingkungan kerja berfungsi dengan baik dan motivasi kerja mempunyai pengaruh pada variabel kinerja karyawan pada kantor cabang PT. BNI, Tbk Medan.

$$
Y=a+b_{1} X_{1}+b_{2} X_{2}+b_{3} X_{3}+\ldots+b_{n} X_{n}
$$

Keterangan: $\mathrm{Y}=$ Variabel terikat (dependen); $\mathrm{X}_{(1,2,3, \ldots . .)}=$ Variabel Bebas (independent); $A=$ Nilai Konstanta; $B_{(1,2,3, \ldots .)}=$ Nilai Koefisien Regresi.

Ditemukan model penelitian sebagai berikut:

$$
Y=26,109+0,065 X_{1}+0,338 X_{2}
$$

Berdasarkan Tabel 1 dapat dilihat pernyataan sebagai berikut: konstanta sebesar 26,109 berarti variabel lingkungan kerja (X1), motivasi kerja (X2) terhadap kinerja karyawan (Y) pada kantor cabang PT. BNI, Tbk. Medan dengan tingkat signifikan 0,000 dianggap tetap. Regresi variabel lingkungan kerja (X1) bernilai 0,065 dengan tingkat signifikan 0,522 menunjukkan bahwa jika semakin naik penanganan lingkungan kerja, maka sangat berpengaruh sekali dalam meningkatkan kinerja karyawan lebih baik lagi dan akan dianggap tetap. Regresi variabel motivasi karyawan (X2) bernilai 0,338 dengan nilai signifikan 0,002 menunjukkan bahwa, motivasi yang diberikan sampai saat ini sudah cukup baik, sehingga kinerja karyawan dapat menyelesaikan tugas-tugasnya dengan hasil memuaskan dan akan dianggap tetap.

\section{Hasil Pengujian Hipotesis}

Berdasarkan Tabel 1 pengujian hipotesis masing-masing variabel menunjukan bahwa variabel lingkungan kerja $X_{1}$ mempuyai nilai thitung 0,643 dengan nilai signifikan 0,522, sedangkan nilai tabel 1.667 dengan tingkat signifikan 0,05, sehingga kesimpulan adalah thitung $<t_{\text {tabel }}$ yaitu $0,643<1.667$, maka hasilnya adalah $\mathrm{H}_{\mathrm{o}}$ diterima $\mathrm{H}_{\mathrm{a}}$ di tolak. Hal ini dapat diartikan bahwa variabel lingkungan kerja sebagian tidak berefek positif dan kurang signifikan pada kinerja karyawan cabang PT BNI, Tbk Medan. Dua variabel motivasi $X_{2}$ memiliki nilai $t_{\text {hitung }}=3,311$ dengan nilai signifikan 0,002 sedangkan tingkat $t_{\text {tabel }}$ 1,667 dengan tingkat signifikan 0,05, 
sehingga penjelasannya adalah thitung $>t_{\text {tabel }}$ adalah 3,311 $>1.667$, maka kesimpulannya adalah $\mathrm{H}_{0}$ ditolak sedangkan $\mathrm{H}_{a}$ diterima dapat diartikan bahwa variabel motivasi sebagian mempunyai efek positif dan signifikan pada kinerja karyawan kantor cabang PT. BNI, Tbk. Medan.

Berdasarkan Tabel 1 dapat diketahui bahwa secara variabel independen berpengaruh dan signifikan pada variabel dependen. Hal ini bisa dibuktikan dari tingkat $F_{\text {hitung }}$ sebesar 9.568 oleh nilai signifikan 0,000 sedangkan $F_{\text {tabel }}$ sebesar 3.13 oleh nilai signifikan 0,05. Terlihat $F_{\text {hitung }}>F_{\text {tabel }}$ atau signifikan $9.568>3.13$ dan $0,000>0,05$, sehingga $\mathrm{H}_{\mathrm{a}}$ diterima dimana variabel lingkungan kerja dan motivasi kerja berpengaruh secara bersamaan dan signifikan pada kinerja Karyawan PT. BNI, Tbk. Nilai Adjusted R² yang diperoleh adalah 0,199 atau sama dengan19,9\% artinya variabel dependen (Kinerja) bisa dijelaskan dengan variasi dari variabel bebas yaitu lingkungan kerja dan motivasi sebesar 19,9\%, dan sisanya 80,1\% dipengaruhi oleh variabel lain.

Lalu diketahui nilai koefisien determinasi atau R Square adalah sebesar 0,222. Nilai $\mathrm{R}$ Square ini berasal dari pengkuadratan nilai koefisien korelasi atau $\mathrm{R}$ yaitu $0,471 \times 0,471=0,222$. Besarnya angka $R$ Square sama dengan $22,2 \%$, angka tersebut mengandung arti bahwa $\mathrm{X}_{1}$ dan $\mathrm{X}_{2}$ secara simultan berpengaruh terhadap $\mathrm{Y}$ sebesar 22,2\%. Dan sisanya $100 \%$ - 22,2\% = 77,8\% dipengaruhi oleh variabel lain di luar persamaan regresi ini atau variabel yang tidak diteliti. Untuk nilai error itu berarti besarnya pengaruh variabel lain, dengan ini artinya adalah variabel $X$ terhadap $Y$ semakin lemah. Tetapi jika nilai $\mathrm{R}$ Square semakin mendekati angka 1, maka pengaruh tersebut akan semakin kuat.

\section{PENUTUP/SIMPULAN}

Lingkungan kerja berpengaruh terhadap kinerja karyawan cabang PT. BNI, Tbk. Medan. Artinya segala sesuatu di sekitar lingkungan kerja dapat mendukung aktifitas kinerja karyawan. Motivasi berpengaruh terhadap kinerja karyawan cabang PT. BNI, Tbk. Medan, motivasi yang baik dapat meningkatkan kinerja karyawan. Lingkungan kerja dan motivasi pada saat yang sama memiliki pengaruh yang signifikan pada kinerja karyawan cabang PT BNI, Tbk. Medan. Maksudnya lingkungan kerja dan motivasi secara bersamaan dapat berkontribusi atau menaikkan kinerja karyawan tersebut. Jadi, jika lingkungan kerja dan motivasi meningkat, maka kinerja karyawan akan meningkat juga, sebaliknya jika lingkungan kerja dan motivasi turun maka kinerja karyawan ikut turun juga.

Rekomendasi yang bisa diberikan untuk manajemen cabang PT BNI, Tbk. Medan dalam upaya menaikkan kinerja karyawannya, yaitu: pertama, lingkungan kerja merupakan salah satu faktor yang dapat mempengaruhi kinerja. Oleh karena itu, kepemimpinan pada cabang PT. BNI, Tbk. Medan harusnya diperbaiki dan memperhatikan lingkungan kerja agar karyawan bisa beraktifitas atau 
menyelesaikan tugas-tugasnya dengan nyaman. Dengan cara memenuhi kebutuhan dan fasilitas-fasilitas yang meningkatkan kinerja karyawan sebagai pendukung kinerjanya. Kedua, atasan atau pihak perusahaan hendaknya lebih memperhatikan dan meningkatkan pemberian motivasi disertai pelatihan kepada karyawan agar lebih baik lagi dalam kinerjanya. Terakhir, agar pihak perusahaan cabang PT. BNI, Tbk. Medan selalu dapat meningkatkan kinerja karyawan dan mempertahankan prestasi selama ini, Perusahaan harus memperhatikan kualitas, disiplin dan kerja sama karyawannya yang telah dicapai saat ini.

\section{DAFTAR PUSTAKA}

Ersan, J. (2018). Pengaruh Bukti Fisik dan Ketanggapan terhadap Kepuasan Nasabah pada PT. Mestika Dharma, Tbk Kantor Pusat Operasional Medan. Jurnal Penelitian Ekonomi Manajemen, Universitas Prima Indonesia Medan.

Hia, f. (2018). Pengaruh Lingkungan Kerja Fisik dan Disiplin Kerja terhadap Kepuasan Kerja Karyawan pada PT. Ikaindo Industri Karbonik Indonesia Medan. Jurnal Penelitian Ekonomi Manajemen, Universitas Prima Indonesia Medan..

Kaswan. (2017). Psikologi Industri dan Organisasi, Mengembangkan Perilaku Produktif dan Mewujudkan Kesejahteraan Pegawai Kesejahteraan Pegawai di Tempat Kerja. Bandung: CV Alfabeta.

Lieadi, D. (2018). Pengaruh Disiplin Kerja dan Konflik Kerja terhadap Kinerja Karyawan pada PT. Halmas Material Center Medan (Distributor Lampu LED). Jurnal Penelitian Ekonomi Manajemen, Universitas Prima Indonesia Medan.

Marsel. (2017). Pengaruh Profesionalisme, Etika Profesi, Pengalaman Auditor dan Motivasi terhadap Pertimbangan Tingkat Materialitas pada Kantor Akuntan Publik Medan. Jurnal Penelitian Ekonomi Manajemen, Universitas Prima Indonesia Medan..

Sinambela, Poltak L. (2016). Manajemen Sumber Daya Manusia Membangun Tim Kerja yang Solid untuk Meningkatkan Kinerja. Jakarta: PT Bumi Aksara.

Pramesti, G. (2016). Statistika Lengkap Secara Teori dan Aplikasi dengan SPSS. Jakarta: Alex Media Komputindo.

Hasibuan, Malayu S.P. (2016). Manajemen Sumber Daya Manusia (revisi). Jakarta: Bumi Aksara.

Samsudin, S. (2010). Manajemen Sumber Daya Manusia. Bandung: Pustaka Setia.

Siagian, I. (2017). Pengaruh Kompetensi dan Pengawasan terhadap Kinerja Karyawan pada PT Jaya Anugrah Sukses Abadi Medan. Jurnal Penelitian Ekonomi Manajemen, Universitas Prima Indonesia Medan

Wibowo. (2016). Manajemen Kinerja Edisi Kelima. Jakarta: Rajawali Pers. 